\title{
Policing Peers and Selves between Law and Morality: A Socio- Legal Perspective on Managing Misconduct in Hunting
}

\author{
Erica von Essen (erica.von.essen@slu.se) \\ Division of Environmental Communication \\ Department of Urban and Rural Development \\ Swedish University of Agricultural Sciences \\ Ulls väg 27, Uppsala \\ Box 7012 \\ Hans Peter Hansen (hans.hansen@slu.se) \\ Division of Environmental Communication \\ Department of Urban and Rural Development \\ Swedish University of Agricultural Sciences \\ Ulls väg 27, Uppsala \\ Box 7012
}

Contact author: Erica von Essen: Erica.von.essen@slu.se; +46-19761989

\begin{abstract}
Contemporary hunting is at great pains to assert a sovereign jurisdiction to state interference. Hunters sometime view laws as illegitimate and cultivate an informal normative order to guide conduct and to protect the integrity and outside representation of hunting in modernity. This involves policing selves and peers mainly from an ethic of fair chase, which is multifaceted. In this study, we interview hunters who reflect on the dynamics of the fair chase ethic as a guiding principle across various dilemmas, including technological gears, commodification of hunting, game allocation and social sanctions over transgressions. Consistent with our socio-legal theory, we observe hunting's moral and cultural perceptions of what constitutes fair chase in many situations is at odds with what is legally proscribed. Our final discussion elucidates the implications of hunters turning away from authorities in these situations, concluding with calls for deliberative culture that can re-integrate moral norms and formal laws.
\end{abstract}

\section{Keywords: norms, ethics, hunting culture, fair chase, Habermas, policing}




\section{Introduction}

Habermas' socio-legal theory holds that when formal state regulation is regarded as untrustworthy and illegitimate, it is because the legal domain has decoupled from the moral and cultural domains in society—in the form of civil norms (Habermas, 1996). What is proscribed by law no longer resonates in moral-cultural norms, but is reproduced by its own internal logic of bureaucracy, often by a government that is increasingly regarded by the public as a baseless 'paper authority' lacking popular support (Gezelius, 2002). Pettit (2012) writes that such legal institutions are likely short-lived when they reign in isolation from civil norms. In Machiavelli's words, "Just as good morals, if they are to be maintained, have need of the laws, so the laws, if they are to be observed, have need of good morals" "(Machiavelli, 1965, p. 241). That the regulatory framework has decoupled from moral norms is a charge that is now increasingly levelled by hunters toward authorities in the Nordic countries (von Essen, Hansen, Nordström Källström, Peterson, \& Peterson, 2015). There is a perception among many in this community that the state has imposed detail regulation that has criminalized traditional hunting practices and is thus at odds with the praxis of hunting.

The primacy of cultural praxis and tradition over comparatively newly created established legal rules is widely substantiated by literature on contemporary Nordic hunting (Heberlein, 1991; Bisi, Kurki, Svensberg, \& Liukkonen, 2007; Krange \& Skogen, 2007). Indeed, here and elsewhere, hunting has retained a degree of sovereignty from state interference that may be owed to three interrelated factors: first, there is no realistic expectation by its members of effective crime detection and enforcement of rules by the state in remote rural areas (Gavin, Solomon, \& Blank, 2010; Bunnefeld, Edwards, Atickem, Hailu, \& Milner-Gulland, 2013). This means local self-rule becomes more important to check behaviour of - and indeed 'police' others - to preserve the integrity and internal order of the institution. Second, hunting is associated with exercising one's freedom in nature (Ortega y Gasset, 1972), including virtues of self-reliance and connectivity to nature's processes (King, 1991; Morris, 2010); hence, detail regulation is seen as restricting one's freedom and choice in this setting. Indeed, in Sweden, a neo-liberal proviso of 'freedom with responsibility' has long characterised hunting, but is increasingly challenged by new rules, EU directives and bureaucracy. Third and finally, hunting has gradually become a sport, which Groombridge (2012) shows means embracing customary rights of non-interference from the state and a reliance on internal rules. Collectively, these three factors contribute to something of a sovereign jurisdiction for hunting. As will be demonstrated, however, the decoupling of the civil norms of hunting from state regulation undermines the legitimacy of hunting as an institution by taking away premises for having critical, public discussions over the validity of laws and norms.

Because of the sovereign jurisdiction of hunting, it has arguably been particularly important for the institution that a robust and principled informal normative code for conduct can step in where formal state regulation is distrusted or shunned in favour or tradition. Such a code is 
essential in maintaining order, which in turn is necessary given hunting increasingly needs to negotiate its legitimacy and justify its practices before modern society (Peterson, 2004). The closest approximation of a normative order for hunting may be found in the thorny ethic of fair chase. However, where before hunters could more easily manage their self-presentation through following a dense system of codes of conduct rooted in traditional conceptions of fair chase, recent developments such as technological gadgets and gear and an influx of paying urban clients now challenge customary norms related to propriety and fair chase.

Against this premise, we observe how formal legal rules are increasingly supplanted rather than validated by a normative order comprised by a suite of moral-cultural codes for achieving propriety in hunting conduct. We contend this moral-cultural code is often a version of the fair chase ethic (Posewitz, 1994). An aim of the paper is to identify, first, to what extent, and in what particular contexts, the normative order around fair chase fails to align with the formal rules stipulated by the legal domain. Second, whether fair chase can provide a sound ethic to guide hunter behaviour in all situations. To elucidate this, we identify a series of interrelated practical dilemmas that today require the hunter to arbitrate between abiding by the law, by cultural convention, or by a moral code of fair chase. Third, we conceptualize the implications of hunting positioning itself as a sovereign jurisdiction in relation to majority society. Using the case study of Sweden, the cultural praxis of hunting that is cultivated parallel to the legal domain may be understood under the mantra 'freedom with responsibility' ('Frihet under ansvar' in Swedish), which facilitates some discretion and moral judgment in hunting. To this end, we pose the related question: to what or whom do hunters hold themselves most accountable today with said responsibility - the state (wildlife regulation and public agencies), the public, hunting peers, wildlife stocks or the quarry? In other words, given a conflict between the moral, cultural and legal domains, which norms have primacy for hunters today?

Our point of departure for this study is Habermasian socio-legal theory as applied to the context of hunting. On this view, we observe that when the legal domain decouples from cultural praxis and morality when it comes to hunting norms, hunters tend to withdraw from discussions from the public and settle matters privately (Janoski, 1998). Ideally for the purposes of legitimacy and compliance with regulation, an actively and publically deliberating hunting community would debate with heterogeneous others in society and so open up for the occasional deliberative critique from non-hunting public. It would also inform via civil norms the content of laws that affect them, holding policy-makers deliberatively responsible for validity claims. In so doing, norms would discursively validate laws and translate into a praxis that was both legal and moral and not one or the other. Such attempts at re-integrating the societal domains has been successfully operationalized, for example, by then-mayor Antanas Mockus in increasing compliance with state regulation in Bogota (Mockus, 2003). 
The paper is divided into four sections. First, we briefly outline the ethic of fair chase to elucidate the dominant moral code that guides much hunting conduct. Second, a method chapter describes the in-depth interview and analytical process behind the study. Third, four contextual dilemmas for hunters when balancing cultural praxis, moral norms and legal rules are presented from empirical data, including technical aids, game allocation, commodification of hunting, and alcohol in hunting. Collectively, they provide timely examples of how hunters' self-policing occur in the intersection between law and morality. In our discussion, we return to Habermas' socio-legal framework to argue that when laws and moral-cultural norms thus decouple, both become exempt from necessary contestation and deliberative scrutiny by each other. Instead, they become validated on the basis of their own internal and uncritical steering logics, including tradition (for culture), bureaucracy (regulation) and market forces (for morality).

\section{The fair chase ethic}

The popular definition of fair chase is that of giving justice to the animal, most commonly manifested by allowing it to use its natural wiles in escaping the hunters' pursuit. Today the concept of fair chase is strongly integrated in North American hunting vocabulary (Posewitz, 1994). The fair chase ethic may be taken as partly rooted in a sports metaphor, as it denotes an internal lusory rule of the game, or guiding principle by which an activity is to be carried out. This became especially important when hunting became more of a leisure activity in modernity and began to face a wide range of advantages following the technological revolution. One needed, simply, a principle of restraint that ensured the balance was not tipped excessively in favour of the hunter over the prey (Gutiérrez, Howard, \& Decker, 1979; Pauley, 2003). To be sure, even before technological shortcuts resulted in greatly increased harvest success, hunting was imbued with taboos and norms in a way that suggested adhering to an ethic of fairness and restraint was important also to native subsistence cultures (Ortega y Gasset, 1972; Noske, 1997).

But inasmuch as the fair chase ethic meant the kind of restraint that could ensure surpluses of harvestable game in the future, its rationale may have been largely anthropocentric (Cahoone, 2009). For one, fair chase has increasingly comprised class privilege. Fair chase was used as the marker that distinguished maximising subsistence hunting - "slob hunting” (Gunn, 2001) - from gentlemanly field sports hunting, to be enjoyed for its own sake, which required artful restraint (Boddice, 2008). That fair chase is often used as a means of discriminating against subsistence hunting is particularly manifest in the case of English fox-hunting. Here, aristocratic hunts constituted the proper way of hunting, while killing for the table (for example by trapping or snaring) was unacceptably "vulpicide” (Marvin, 2007). In developing countries the credo that “...in all true hunting, process outranks project" (Petersen, 2000) reflects neo-colonialism, where indigenous are characterized as poachers while well-off westerners constitute the 'proper' ethical hunters either through their sportsman code, or through presenting their hunting practices as the stewardship of the ecosystem (MacDonald, 2005). 
Today, technological advancement may undermine the ethic of fair chase as it presents the hunter with advantages that can significantly increase harvest success. Motorized vehicles, highscoped rifles, baiting tools and tracking devices (e.g. motion detecting cameras and high resolution radar) dramatically shift the balance in favour of the hunter and facilitate new practices across previously untraversable terrain (Pauley, 2003). Indeed, there is now sophisticated remote sensing aerial hunting technology to the point of military fetishism (Wall \& McClanahan, 2015) where gear can pinpoint the location of game with striking accuracy and send a photo directly to the hunter's smartphone. It is interesting to note that these are conveniences chiefly available to sport hunters of means who have previously prided themselves on adhering to an ethic of fair chase. Subsistence hunters, meanwhile, often rely on less spectacular technological equipment, but likewise adapt to new advantages.

Fair chase can thus no longer be said to be associated with one particular type of hunter. It is both an ancient internal logic to hunting and a pragmatic approach to ensure surpluses of game for future generations. To capture the dynamics of fair chase, therefore, we part with previous research on hunters which has overwhelmingly either separated hunters into discrete profiles in typologies based on their approximate positions in relation to fair chase (Kellert, 1978), or at best suggested hunters might progress through these categories in their lives (Eliason, 2004; Raija \& Jarno, 2013). In contrast to prior research, then, we do not see that the average Swedish hunter inhabits discrete profiles like 'sport', 'slob' or 'stewards', but rather than he or she may continuously be reflecting and acting upon competing conceptions of the ethic of fair chase when hunting. These often involve a tension between honouring the art and propriety of the hunt and achieving efficiency. This point of departure finds precedent in Kuentzel (1994) and Marvin (2013), who argue hunting categories must be re-orientated as dispositions contingent on situational factors and social influence that can be experienced by the hunter at various situations.

Herein a premise is that accommodating both fair chase as a moral standard and the harvest efficiency with which cultural praxis in hunting is currently enabled, presents a balancing act that may be vulnerable to various forces, not least including market prices and technology in the current neo-liberal paradigm. The hunter must navigate through such dilemmas through arbitration (Simpson \& Cain, 2000). Indeed, he or she must achieve this balance between fairness and utility because the public today may only accept hunting if it is seen to satisfy utilitarian ends of wildlife management and meat procurement on the one hand, and encompasses the use of propriety and skill. In what follows, we relay these dilemmas as they pertain to the tension between fair chase and efficiency and, in so doing, display hunters' reflections on fair chase and conflicting allegiances to different normative orders. 


\section{Method}

We conducted a total of 28 in-depth interviews with hunters across Sweden. We cast a wide net to access new hunters, female hunters, urban hunters and a range of specialized hunters (trackers, bird enthusiasts, big game hunters, competitive shooters and professional hunters) across an age range from 25 to 90 years of age. Respondents were selected through a snowball sampling method that operated from a tripartite point of origin with the aim of achieving data triangulation to capture diverse voices (Bryman, 2004): contacts from the Swedish Hunting Association or the National Hunters Association, personal contacts to the researchers, and eliciting the perspectives of hunters from a popular online hunting forum, Robsoft. Each respondent was asked to suggest additional names in any part of the country to facilitate snowballing.

The 28 interviews constituted three quarters of the total interviews completed for the larger FORMAS-funded research project Confronting challenges to political legitimacy of the natural resource management regulatory regime in Sweden - the case of illegal hunting in Sweden in which questions to hunters centred on the perceived legitimacy of laws and decision-making processes pertaining to hunting, wildlife conservation and game management. Respondents reflected on situations where they did not agree with a law, knew someone who had broken it, and on what they reasoned to be the right thing to do in the particular hunting situation. By proceeding discussions on distrust of authority and hunting's place in society, dilemmas could be better positioned in their socio-political and legal contexts.

We employed an inductive research process whereby respondents arrived at the dilemmas, rather than imposing any a priori framework. Interviews were $1 \mathrm{~h} 20 \mathrm{~min}$ to $2 \mathrm{hrs}$. in length and semi-structured in nature. Because of the sensitive nature of questions pertaining to law-breaking, anonymity and indirect interview techniques were utilized (Rubin \& Rubin, 2011). One approach was to ask respondents if they knew someone who had committed a hunting crime when faced with these sorts of dilemmas and what they made of types of illegal hunting and moral grey zones where there was elbow room between norms and laws (Gezelius, 2002). Second, adapting the premises of recent success in indirect interviewing with illegal hunters in Finland (PohjaMykrä \& Kurki, 2014), they could also be presented with hypotheticals that inquired what one might do in a given situation of moral ambiguity. Trust was established in the interviews in part via a shared positionality with the respondent through the interviewers' hunting backgrounds (Mullings, 1999). From verbatim transcriptions, we open-coded predominant dilemmas and tensions in relation to fair chase and efficiency, into four themes: technical aids, game allocation, commodification of hunting, and alcohol and hunting. While the former three showcased cultural praxis and morality conflicting with the legal norms and sometimes also with each other, the latter theme mainly addressed how hunters dispensed with social justice when there had been a norm violation or legal infraction within their hunting team. Collectively, reflections illustrated 
the extent and implications of upholding a sovereign jurisdiction for hunting in modernity, including a de facto lack of deliberative reflection.

\section{Results}

\section{The need for a hunting code}

In what may surprise some, hunting is a context that despite an unenforceability of much regulation due to its remote rural character is not characterized by lawlessness but by adherence to all manner of rules of conduct. We found it is a context of self-policing, social sanctions and adherence to an honour code or sportsman ethic. In this way, its relative self-containment and de facto autonomy from the legal domain seemed to pose higher demands on assiduity of conduct. As three respondents argued:

"You have to understand that we can only hunt for exactly as long as the majority of the public finds hunting acceptable"

"If we're to keep hunting we need to do so in a principled manner [...] if there's no acceptance among the general public we won't be allowed to keep doing it"

"This representation of us, it's something we ourselves control, and it might be the greatest threat"

Respondents also noted that principled hunting needed to be both on the level of the outside representation one projects to majority society and on the level of internal propriety: "You have to abide by the rules and practices of your hunting team" so as to not be excluded and ostracized in rural communities, or gain a reputation as an irresponsible hunter not versed in the cultural conventions of the hunt. "Probationary” periods entailed evaluations of new people: "If you're not happy with him after a year he will probably get a longer probation”.

At the same time, when asked about arenas for actually reflecting on current cultural praxis in hunting and ventilating ethical issues, respondents often indicated there were no clear fora, but that such things came intuitively from one's hunting background, often from particular mentor figures in one's family or social network. When asked about arenas for discussing wildlife management practices, the situation was worse. Contentious management schemes, particularly concerning state protection of wolves, it was contended, are so inflammatory that mere discussions could invite outside scepticism. As three respondents noted of controversial issues: 
"They are simply never discussed. Nobody says anything”.

"We never raise these issues in the team. Maybe one should do that."

"We've been over it so much in the past so no one cares anymore $[. .$.$] we don't have the energy for it."$

The latter respondent suggested prolonged lack of uptake on the part of the authority could result in illegal hunting, where one simply was fed up with marginalization by the authorities.

That said, respondents tended to staunchly oppose unlawful hunting and declare poachers the scourge of the community. In a majority of cases, hunters attempted to de-label poachers as hunters so as to not taint the hunting establishment and by explaining that these were killers or criminals — who happened to be hunting. Hunting after hours, for example, “...is not hunting" per definition. This is a common refrain to delegitimize hunters who are perceived to have a contaminating effect on the hunting institution (Raija \& Jarno, 2013). A respondent suggested "You have to distance yourself from those freaks. You need to have a system in place that protects your institution." Respondents were thus cognizant of the position of hunting in modern society, and the observation that "hunters are hunted" surfaced repeatedly in interviews. Negative events tended to be magnified in the media, it was argued, in large part because of the tenacity of animal rights organizations in "sensationalizing" hunting law transgressions. Although approximately half of our respondents were optimistic toward the future of hunting owing to newfound popularity of back-to-nature hobbies, another half feared for the contaminating effect of certain types of hunting and certain types of hunters associated with what society deemed now unethical which centred on the excesses enabled by technology and money entering hunting. "It is screwed up because it gives the collective of hunters a bad name. This directly leads to increased outside regulation for us" These were often associated with new urban hunters who had been deprived of the cultural praxis in hunting and thus lacked a robust code and sense of how do to things. This made resultant dilemmas and norm violations all the more important to resolve ethically at the level of the private sphere where such things could be contained away from the public gaze. In what follows, these main dilemmas are summarized.

\section{Technical aids}

The use of technical aids constituted one of the most pronounced sources of disagreement among the hunters we interviewed. Those who hunted with hounds tended to be favorable toward the use of GPS, stating that it saved them a lot of time and trouble in locating coursing dogs after hunts. Hunters without dogs, which constituted nearly half of those interviewed, were on the whole moderately more sceptical toward the popularity of GPS; three respondents suggested preoccupation with this device could detract from the reality of the hunt. One 
contended that when you're out there "...with wires and antennas coming out of every direction" trying to "...be one with nature”, technical aids should be used sparsely as every little thing detracts focus from the hunt. Another respondent said: "I don't like [technical gears] because hunting is supposed to be simple. The reason I hunt is to evoke the primitive in me.” More practically, three dog-less hunters criticized other hunters for abusing the GPS aid, intended to track dogs, for lazily tracking the movement of the game being chased and turning up at strategic points with their cars.

“That's more like watching TV than hunting”

"It's not hunting. It's something else. Of course, if you'd say you'd catch up the game on foot, I'd wish you good luck"

"It's good in a way. But if you look at it ethically you can basically stand there and when you see it's moving another direction you move with it... I mean, the game needs to have a fair chance."

All respondents expressed criticism toward the use of motorized vehicles and noted how this was a phenomenon that they had often come across "in other hunting teams", in other regions and similar. "Today it's essentially possible to get out a helipter and shoot moose or whaetevr you want. But what kind of hunting is that?”. Respondents also referred to a more common practice of cutting the game off at strategic junctures by taking one's pick-up truck or ATV. Within this they indicated vehicular shooting or tracking was frowned upon and a violation of fair chase, and sometimes associated with poaching practices: “There's a silent agreement that you simply don't shoot from your car”. But others observed that within this, grey areas could potentially be discerned. For example, the old man with the bad legs was largely justified in parking his pick-up near where he would shoot the animal:

“Nisse, aged 87, shouldn't have to walk that far. That site is then $20 \mathrm{~m}$ from the road. If he parks his car $20 \mathrm{~m}$ from it he has supposedly committed illegal hunting".

Similarly, respondents suggested that one sometimes drove the car from point A to point B and walked a shorter distance to get to point $\mathrm{C}$ where the animal had been sighted.

Erecting motion sensitive cameras for wildlife on your lands, such as near a supplementary feeding station for wildlife, is illegal without permit from one's County Administrative Board. This is based on laws enacted to protect the privacy of citizens from video surveillance, and so 
are external regulations rather than rules that form part of the internal logic of hunting. Perhaps for this reason, the vast majority interviewed thought very little of the prohibition.

"In my opinion you've really missed updating the regulation when it comes to camera surveillance".

“That's a real clusterfuck”

That the prohibition is not grounded in hunting norms is reflected in national statistics where hundreds of thousands of wildlife cameras have been purchased, but applications for licenses and actual permits granted significantly fall short of this (Folkbladet, 2011). As one hunter candidly conceded," We ignore that rule completely. Honestly, first someone has to find [the camera]."

Approximately two-thirds of those hunters critical toward the camera prohibition suggested most people ignored the legal proscription and were themselves critical toward what they saw as a nonsensical "silly", privacy law interfering in hunting praxis. Because these cameras are mainly mounted on private land, moreover, they could not see a moral violation if a person was caught on camera - after all, he was transgressing on their land. "I mean, how many people move around there?" Surveillance cameras additionally contained an essential device for the autonomy of hunters by providing a direct link to wildlife populations that bypassed the often untrustworthy or distorted information provided by management authorities. As such, documentation from cameras could challenge the legitimacy of the authorities by showing alternative versions of events: "Take bears, bear tracks and that sort of thing. No one in hell believed them until they caught them on camera and then it was a settled matter."

Another dimension that promoted ambivalence toward the use of wildlife cameras and scepticism toward its prohibition in law was the recognition that as a technical aid, it could potentially make one a more responsible, and thus ethical hunter. Cameras, along with spotlights for nocturnal game, were argued to enable better inventory of wildlife and thus result in more informed target selection based on e.g. avoiding breeding individuals. Spotlighting rifles by baiting stations at twilight and night hunts could also facilitate instant kills by reducing the risk of maiming the game, even if this potentially violated fair chase as cultural praxis.

"Most technological aids I think... I'm for them... they mean better opportunities for more ethically sound and selective hunts. All that stuff helps.”

"Everything that enables hunting to be done safer. More successful hunting. One ought to support that." 
The tension between ethics and laws, moreover, was declared by one respondent as "The ultimate dilemma. There are always two sides".

\section{Game allocation}

Several respondents expressed criticism toward moose management areas that specified the season's allocation of targets, in this case, for moose. They contended that the boards are dominated by the forestry interest, whose private corporations have disproportionate say on the ecology behind management strategies.

"The forest owners have a very big say which is reflected clearly in the increased allocation of moose in recent years. In a way that completely decimates the populations. So you've got this distortion that's not grounded in ethical thinking. It's economics."

Indeed, hunters claimed to often purposely shoot fewer animals than on the official quota because they feared the board of the moose management area was out to decimate the moose population: "As far as I'm concerned, the moose stock will be devastated within five years."

This reflects an entrenched conflict between hunters and forest owners in Scandinavia (Wam, Pedersen, \& Hjeljord, 2012). Indeed, wildlife conservation and personally tending to stocks was both an individual norm and a shared cultural strategy. If they went ahead and shot valuable breeding individuals either by mistake or intent, hunters were socially sanctioned in their teams, often by their hunting leader. "It's extremely frowned upon, otherwise you mistax[snedbeskadda] the population”. In rarer cases where additional animals had been shot through carelessness, most had owned up to the transgression and accepted the legal consequences. This was surprising, but more than a legal infraction, it was also seen as an "act of disrespect" toward one's hunting team and required sanctions for this reason. Hence the faux pas typically resulted in 'great shame" on the part of the offender and having to give up the trophy and meat, "they'll just hang [the antlers] at the butcher's".

\section{Canned hunts and commodification}

Approximately half of respondents reflected to some extent on the capitalist turn in hunting, comprising market hunting, game ranches, the trend of purchasing of hunting opportunity in hunting safaris and related fish-in-a-barrel practices. Here, "the commercialization around hunting is probably the biggest problem" in relation to the integrity and outside representation of hunters in modernity. One respondent recalled the experience of 100-hectare game ranch thusly. When it came time for a convalescent old bull to be euthanized, a specially engineered breed of 
meat animal from Poland, organizers decided to sell the hunting opportunity for a steep profit. He recalled the artificial set-up of this privilege to hunt:

“...they would herd this big convalescent beast around, but secretly of course because the hunter was supposed to feel like he was doing some hunting. And then at the end when you got him moving in the right direction you were like 'oooh, there is, go get him'.”'

This trend was dismissed on account of its lack of fair chase, questionable animal ethics, its overemphasis on trophy kills, and its reduction of the hunt to a matter of shooting. It was taken to stop short of the 'freedom with responsibility' proviso, moreover, because it was ultimately “...on someone else’s terms”. However, other respondents intimated canned hunts were problematic precisely because they involved the uncritical and automatic acceptance of the client's style and ethic. One respondent, for example, recalled from recent experience of wildlife safari that standards of ethics in these situations tended to be adapted to whatever client one was catering: "If a client has spent several hundred thousands to go down there it's hard to escape". In this way, when trophy hunters who cared very little for the virtue of the hunt or for the animals in their wild habitat fronted the money, tour guides simply had to accommodate them. Reflecting about faux pas, one respondent expressed a concern over the lack of ethical accountability that befell a high-paying client after he had maimed wild boars. "He should be excluded from hunting. [But] the guy who had sold him the hunt didn't dare make that decision"

Another respondent explained it in the following terms:

"It's like any other economic transaction. It's an exchange.

You trade something for something else. And sometimes because of the high cost of the hunt you need to bring in people who might not be that skilled, but if they pay enough money we also have to listen to this person and that affects the hunting, the hunting ethic."

and

"Does it matter that the lion or the cow that's 200 m away has a collar around its neck and is perched by the tree? You've paid for the pleasure. You'll be bringing those antlers home. Does it matter?" 
A third respondent argued that with the trend toward making hunting possible for even the "wheelchair bound half-blind people in pick-ups" if they paid for the pleasure, ethics were now stretched to their breaking point. The issue was raised by other respondents in regard to the situation in Sweden, particularly with wild boars as an upcoming popular "sport kill” quarry to be commoditized. Money, greed and commercial hunts were taken to “...bring out the worst in hunters” by several of our respondents.

These respondents tended to view state regulation most positively insofar as it was able to discourage irresponsible trophy hunters. This denoted a contrast to the aversion expressed toward state regulation in other hunting contexts, like camera surveillance and the establishment of moose management areas for determining quotas. Nearly all saw commodification of hunting becoming a stronger trend in modernity, and three respondents had enjoyed hunting safaris abroad. They attributed the increase in this trend to two reasons. First, the increasing cost of leasing hunting land which would promote one-off costs for hunting experiences. Second, the hectic pace of modern living imposed time restraints where hunters needed to maximize kills once in the field. This led some respondents to suggest that expensive land leases, particularly in the south of Sweden, engendered a certain type of ethic that was more maximizing of yields:

"On some level, when you purchase a hunt for a cost you have to make sure to maximise it”.

"It has the effect of my having to shoot because I pay so much money for the trouble [...] at the same time as order and propriety are needed I have to get a return on my money.”

Other respondents suggested illegal hunting would increase owing to rising costs associated with hunting. One said:

"It's so bloody expensive to hunt and to acquire hunting land so there's this development toward more thievery because it's just so damn pricy."

Higher costs were thought by others to have “...an effect on morals and ethics and norm," and urban hunters maximising their investments when hunting meant, for an another respondent:

"... more hysteria, get the dogs in and things have to happen immediately and pang a shot and then you have to get home by noon." 


\section{Hunting under the influence}

Finally, with the aim of deducing how discipline, discretionary powers and informal enforcement might work in teams to secure ethical hunts, we approached our respondents with the issue of alcohol in hunting. Older hunters highlighted that alcohol in hunting has decreased significantly in their generation. Most expressed a zero tolerance policy toward alcohol before or during the hunt. A few had experience of scenarios where such ethics were stretched, many from international contexts, and some from "backward redneck hunters" during the annual moose hunt. The latter tradition being something of a celebratory affair for hunters, where alcohol has traditionally featured.

Enforcing sobriety within hunting teams was largely at the discretion of peers and the hunting leader. Several respondents relayed how they had spoken up about someone under the influence, often resulting in the exclusion of the hunter. There were issues, however, including a discomfort in having to take on a policing role toward a friend. Many saw this as being the purview of the leader and not one's place to interfere. If this was a repeated offense, however, the hunter could usually expect to lose his place on the team. If it were isolated incidents, respondents suggested he could be driven home, given a different task, or receive some form of probation on account of his transgression. "If someone shows up and you notice he's smashed he will be sent home that morning”. The transgression was seen as both social, constituting a betrayal of one's peers by putting them and their dogs in danger, and an ethical violation by increasing the risk of wounding wild animals with poorly aimed shots or an excess of bravado. But it was never brought to the authorities:

"It's a bit like when you notice someone gets sloppy

with their bullets, of course you broach the issue then and there, you don't report it to the authorities. It's not a police matter to me. It's a selfpreservation thing."

Social sanctions were taken as a way to "sort through the people you like hunting with" that could be applied to more transgressions beyond inebriation. 


\section{Analysis}

Acquiring a moral stamp as a hunter was socially important to be included in teams and to be invited along for other hunts; it was ethically the right thing to do at a time when technical shortcuts could turn hunting into a "video game". Finally, it was imperative to project a virtuous character to the rest of society when issues amassed controversy with the influx of technology, commodification and urban hunters at the same time as the general public became more environmentally conscious and critical toward hunting's place in modernity. Given this predicament, the reasoning was that the more they mess up and make bad choices, the less freedom and the more restrictions await them. Hence, we find that hunting is anything but anarchic in its occasional resistance of state regulation insofar as it cultivates micro normative system to maintain internal order and secure acceptance by the rest of society.

The level of discord we encountered, however, reflects the supposition that ethical standards spanning different hunting practices are not canonical within Swedish hunting culture. Assessments of fair chase in different situations remain squarely in the realm of subjective opinion and diverse cultural praxis until they cross into legality, provided they reach this point at all. But hunters recognized a danger to consecrating proscriptions into formal laws because to do so tended to exempt them from discussion and contestation that ought to take place over hunting norms. As our findings showed, the legal domain sometimes comprised 'ridiculous' proscriptions that hunters either navigated around or violated anyway because they were incongruent with cultural praxis and moral norms on the ground. These included the wildlife camera monitoring prohibition, high local quotas on seasonal moose harvests, or the fact that such things as canned hunts and imbibing alcohol was technically legal during hunting, thereby requiring social control and peer-policing in teams anyway. Previous research has suggested official quotas rank low for local users in terms of resource appropriation rights, which are often underdetermined by a mix of cultural praxis and moral norms (Ostrom, 2005; Thomsen \& Davies, 2007). Insofar as hunters engaged in self- and peer-policing according to their internal code, exclusions from teams and gossip constituted sanctions not dissimilar to how penalties are imposed in the sport context for "bringing the game into disrepute" (Foster, 2006).

\section{On the Limitations of Fair Chase as a Guiding Principle}

A particularly interesting correlation we noted was that the hunters who prided themselves on their adherence to the moral code of fair chase often vehemently opposed the commodification of hunting, arguing that such hunters were not true hunters. The taboo is a common refrain within hunting scholarship. Leopold (1946), Ortega y Gasset (1972) and Loftin (1984) are especially pronounced critics of artificial hunts. Indeed, Loftin (1984) terms it "The single most alarming trend in hunting today" (p. 249) toward which the most effective weapon is ridicule. Equally, stalwart hunting defenders argue that it turns wildlife managers into brokers 
and shooters and hunters into clients who purchase the commodity (Causey, 1989). Critical scholars liken game ranches to slaughterhouses (Pauley, 2003), brothels (Causey, 1992) and noisy, tacky video games or amusement parks (Peterson, 2000). In addition to undermining conditions for other hunters and inviting the scepticism of society, Gezelius (2002) explains the aversion as due to the symbolic contamination of relationships by money and commercialization.

Insofar as one opposes commodification and technological shortcuts based on an ethic of fair chase and alleged respect for the quarry, we note a disparity between fair chase as a moral code on animal welfare and fair chase as cultural praxis. Above all, reflections raise the question 'fairness to whom?' From an animal welfare point of view, game ranches may entail swifter deaths through the use of often high-powered rifles at close distances, conservation value (Bunnefeld et al, 2013) and less suffering for animals when compared to natural hunts that take fair chase to an extreme, for example, by doing away with any technological aids, by perhaps using a bow-and-arrow, and by often ritualistically subjecting one's prey to a trial of stamina to honour its natural wiles, causing it undue stress, and have it running for hours on end displacing it from its kin and habitat (Marvin, 2003). Indeed, by contrast, the paying client may in this way achieve a more honest, swift kill by getting in and out in the allotted time to secure his trophy, an outcome that may be more important than the process (Gunn, 2001). With this we do not mean to suggest game ranches represent any sort of future for hunting, especially given ethics are imposed in market transactions. But we see that fair chase and its code of propriety appears at times to have detached from animal welfare concerns, to the extent they were ever about this, and centre instead on the use of skill, art and respect to fellow hunters, sometimes to the detriment of the quarry.

Van de Pitte (2003) comes close to putting her finger on the issue of 'fairness to whom' when she identifies that the fair chase as cultural praxis appear to centre on respecting property rights, on not endangering residents or offending others' sensibilities by inappropriate displays rather than anything else. Hence, the proviso of freedom with responsibility, which as contended naturally begs the question: responsibility to whom, is clarified. Bag limits, quotas and propriety are followed, first and foremost, so that other humans can enjoy the sport. Van de Pitte's conclusions suggest that the ethic of fair chase thus has an anthropocentric and social-humanist component rather than a species egalitarian one. The ethical standard to which fair chase is held is that it promotes courage, self-reliance, skill and honour - among humans.

Of course, the potentially anthropocentric praxis in fair chase does not preclude the ethic from also having subsumed genuine sensitivity to animal welfare to a greater degree today. For one, taboos and fairness restrictions in harvesting can originate in the most dubious anthropocentric practices but still go on to have a role in conservation (St John, Edwards-Jones, \& Jones, 2010). Similarly, Samuel (1999) and Scruton (2000) note that piety toward works of nature has gradually infused the fair chase ethic, while Gezelius (2002) finds orientation toward 
conserving the common good often features. Indeed, in the US, we found Boone \& Crocket's definition of fair chase specifies that practices are both legal and ethical. This would seem to indicate that fair chase is held to a higher integrative standard than the two; it subsumes both. That fair chase encompasses several spheres, including hunting ecologically informed, socially tolerant and fair in terms of minimizing suffering toward animals surfaces elsewhere (Simpson \& Cain, 2000). But, others take seriously the anthropocentric praxis of the fair chase ethic, charging it with being a cosmetic cover-up that codifies what is actually ruthless efficiency behind many trophy hunting clubs like Boone \& Crocket and Pope \& Young (List, 1998).

\section{Implications for the place of hunting in society}

Our premise was that disharmony between cultural praxis, morality and legal rules engendered dilemmas for hunters in their everyday praxis. The tensions between honouring fair chase and maximizing harvest efficiency appeared as the leading source of tension that set the hunter adrift between these societal domains. Now, what can we reasonably make of the internal normative order practiced by respondents? On the one hand, the presence of individual reflection on propriety should be regarded as a strength of the culture that should be cultivated. Indeed, Leopold (1946) argued hunting ethics - particularly the thorny and evolving ethic of fair chase should not be a priori fixed, but formulated and practiced by the individual in embodied experiences. The relatively high degree of autonomy and willingness to create their own cultural praxis parallel to the legal realm suggests hunters are cognizant of the seriousness of their practices and can spot unjust, impractical or outdated rules that violated received wisdom of fair chase. While such behaviour has been cynically traced to a pursuit of the public's moral stamp of approval today given hunting's controversy, revalidated by our respondents, it does not debar hunters from genuinely seeking to honour fairness and animal welfare in their hunting practices and becoming reflexive.

On the other hand, the foregoing findings testify that it may be undesirable when arbitration in these dilemmas over moral, cultural and legal tensions is predominantly sporadic and confined to the individual. For one, it is of course worrisome in the first instance that legal rules are seen as unjust, untrustworthy, and lacking in legitimacy in the first place. The Swedish hunting associations' neo-liberal proviso “freedom with responsibility” may pose an attractive escape from detail regulation that suits the rural, autonomous and custom-regulated character to hunting. But this sovereignty asked much of the fair chase ethic to sort out misconduct before any contaminating events leak to the non-hunting public. One respondent suggested the pressure should ideally be placed on knowledge and education in ensuring proper conduct as means of keeping detail regulation at bay, though they failed to mention whose sense of propriety should provide the normative standard or how one might arrive at a consensus on this.

Our results, however, indicate that in practice it is not education that gets to shoulder this burden. As contended, knowing right from wrong came from one's background and intuitively 
from experience in the field, rather than the outcome of public discursive processes. Where the fair chase failed to cement a normative order, our hunters demonstrated an informal institution of self-policing misconduct among hunters had to do the heavy lifting. Self-policing means going to the authorities was rare, save for cases where quotas had been violated, and passive enforcement in the form of gossip, slander, speculation and social exclusion featured instead so as to 'contain' hunting transgressions. This is consistent with ethnographic studies into the Nordic context, where unwillingness to become the subject of gossip provided stronger impetus for compliance with norms than did legal decrees (Gezelius, 2002). While laudably optimistic about the capacity of citizens to deliberate conscientiously and among their peers in private settings, an aversion to regulation has also meant that hunting culture has been bereaved of a public platform in which citizens can deliberate. This was less of an issue when the norms of society were more or less shared by the hunting culture, but today there is manifestly controversy around values. Consistent with our normative premise, one requires a discursive platform to legitimate law as an institution by deliberation among diverse actors. Beyond fora in which political representatives and policy-makers can critically defend their proposals before a hunting public, opening up for deliberation must also be seen as in the interest of hunters, who can articulate grievances. However, there is no platform, or at least no praxis, associated with raising common issues in hunting ethics because it may, unhelpfully, be seen as encroaching on the private autonomy of hunters or be elsewise taboo. There are, however, arenas that could realize this potential for a deliberative and reflexive praxis among hunters today, notably the Swedish Hunting Association, which hold strong membership rates and a good relationship with the state.

If we tie this more explicitly to Habermas' socio-legal discourse theory, we find both private and public autonomy are sought in societal issues. Absence of the latter has the following implications, as intimidated by our findings: first, hunting has become a private and largely individual matter whose thornier issues remain undebated in public settings within the hunting establishment. At best, discussions may arise within hunting teams but are generally scarce. As revealed by hunters' experiences of hunting safari, the individual's hunting ethics could also be transactionally imposed on the hunt through a fee, bypassing any deliberative stage (Habermas, 1996). Similarly, increased costs of leasing hunting land in some parts of Sweden imposed a certain ethic of maximizing yields, especially among pressed-for-time urban hunters. Second, the lack of public deliberation left hunting questions to the mercy of the informal institution of tradition. Tradition, moreover, bypasses citizens' critical faculties that are required when adjudicating moral dilemmas (Rostbøll, 2008). Indeed, the "way in which it has always been done" left a potent legacy that arguably precluded the fair chase ethic from evolving to a point where it could withstand rigorous contestation. In the case where hunting decisions are institutionalized, as in the case of the moose management areas, the situation was little better as common questions were turned into private interests to be resolved by representatives of commercial interests. Needless to say, this forum does not represent a satisfactory public 
rendition of common questions for hunters, as was readily demonstrated in deviations from and disapproval of quotas from this platform.

There may be self-evident reasons why public deliberations on controversial issues and dilemmas raised by the existing hunting practice are not sought by hunters today. First we argued that it was seen as interfering with one's private autonomy and custom of the sport and, perhaps, status as self-reliant hunter and steward of one's land. Second, we have argued hunting needs to carefully negotiate its legitimacy in modern society (Peterson, 2004). To open up for a representation that may appear fragmented, messy and self-critical to the non-hunting public, factions of which remain eager to seize on contested issues, means opening the floodgates for further criticisms, potentially from an uncontrollable outside public. Interestingly, the police force has recently been investigated as a site guided by an internal normative order and 'code of silence' so as to protect against public criticism (Long, Cross, Shelley, \& Kutnjak Ivković, 2013). In a similar way, moreover, this too concerns a culture that purchases its autonomy at the high cost of further alienating themselves from the public by closing doors to deliberation and transparency around contested issues. Substantiated by our findings, certain things in the hunting context, it was contended "...there is no point to bring to the public because all they do is provoke [...] you have to be very careful when you voice opinions”. Unwillingness to publically engage in discussions on norms has the effect of resigning them to the shackles of tradition and economic media.

We contend fora are needed that permit the ventilation of thorny issues, fora that harnesses the often profound reflexivity we encountered in members of the hunting community. Beyond a strictly Habermasian idea, the call came from a few of our respondents:

“Why don't we put together some sort of joint forum so we can collaborate and find common ground in these questions?"

Another argued that:

"That which unites us is so much greater than that which separates us. Why don't we put together some sort of collaborative forum where we can deliberative and find common value grounds?"

Mini-publics of randomly selected hunting citizens may provide a way forward that can subject norms and traditions on the one hand and legal rules on the other to critical reflection (Böker \& Elstub, 2015). In particular, a critical public discussion is needed on practices related to fair chase as this is manifestly most divisive. One might anticipate the counter-argument by 
some sport hunters; namely, because hunting is in part a game today, its lusory rules are sovereign and simply off-limits to critical public discussions (Groombridge, 2012). They are, simply, part of an internal logic of hunting. This argument, however, becomes difficult to substantiate. As Cohen (2003) Cohen (2003) posits, the rules that now qualify hunting as a sport or game, were less a coherent design created by its inventors than rules that were gradually enacted to (1) protect hunters in modernity and (2) save resources to enable future playing of the sport. Its rules are hence mutable and malleable, and such rules even when they concern private associations demand rational, moral deliberation for continued justification of the activity (Wade, 1990; Rawls, 1999).

\section{Conclusion}

Hunting in Sweden is characterized by a dense undergrowth of norms on right and wrong, which are undergoing change. The paper found an absence of a deliberative platform where, first, cultural praxis, such as the ethic of fair chase, could be put to scrutiny and, second, where policymakers, political representatives and hunters can meet to contest and defend claims. We argued hunting culture has gradually become integrated on the basis of its own logic, resulting in a schism between the legal domain and moral-cultural order. This rendered hunting vulnerable to the following three forces. First, conceptions on fair chase had to shoulder a heavy burden behind decisions. Second, cultural praxis and tradition were looked to, sometimes uncritically, as guiding points. Third, norms and ethics became contingent on economic media, whereby high prices for canned hunts and for leases was speculated by hunters to incur an indiscriminate maximization ethic and potentially promote illegal hunting respectively.

In our Habermasian socio-legal perspective, it is striking to see the market and private sphere informal control have emerged to coordinate action in place of public processes. While critical toward hunting becoming a private matter, we did not suggest increased detail regulation be the way forward. Rather, we suggested the societal domains need to inform each other through discursive legitimation as suitable platforms that simply need to seize on and cultivate the praxis of engaging in such deliberation. Only then can one achieve effective crime control that is consistent with people's moral-cultural sense of what is acceptable conduct. In so doing, the legal can be validated by cultural praxis of democracy in which deliberation is informed by norms and ethics. This is particularly important to bear in mind given hunting's societal role today; its often resented subjugation to EU directives and, in Sweden, recent ideas on establishing a new hunting agency with a clean slate to optimize compliance from hunters.

\section{Acknowledgements}

This work was supported by The Swedish Research Council Formas' annual open call (2012) for applications for research and development project grants, and the Gunnar and Lillian 
Nicholson endowment. The grant was awarded to the project "Confronting challenges to political legitimacy of the natural resource management regulatory regime in Sweden - the case of illegal hunting" [grant numbers 2012-7896-23062-36].

\section{References}

Bisi, J., Kurki, S., Svensberg, M., \& Liukkonen, T. (2007). Human dimensions of wolf (Canis lupus) conflicts in Finland. European Journal of Wildlife Research, 53 (4), 304-314. https://doi.org/10.1007/s10344-007-0092-4

Boddice, R. (2008). Manliness and the "Morality of Field Sports": E. A. Freeman and Anthony Trollope, 1869-71. Historian, 70 (1), 1-29. https://doi.org/10.1111/j.15406563.2008.00201.x

Bryman, A. (2004). Triangulation and measurement. Loughborough: Loughborough University.

Bunnefeld, N., Edwards, C.T.T., Atickem, A., Hailu, F., \& Milner-Gulland, E.J. (2013). Incentivizing monitoring and compliance in trophy hunting. Conservation Biology, 27, 1344-1354. https://doi.org/10.1111/cobi.12120

Böker, M., \& Elstub, S. (2015). The possibility of critical mini-publics: Realpolitik and normative cycles in democratic theory. Representation, 51(1), 125-144. https://doi.org/10.1080/00344893.2015.1026205

Cahoone, L. (2009). Hunting as a moral good. Environmental Values, 18 (1), 67-89. https://doi.org/10.3197/096327109X404771

Causey, A.S. (1989). On the morality of hunting. Environmental Ethics, 11(4), 327-343. https://doi.org/10.5840/enviroethics19891141

Causey, A.S. (1992). On sport hunting as an instinct. Environmental Ethics, 14(4), 377-378. https://doi.org/10.5840/enviroethics199214411

Cohen, J.A. (2003). Is hunting a sport? International Journal of Applied Philosophy, 17(2), 291326. https://doi.org/10.5840/ijap200317220

Eliason, S.L. (2004). Accounts of wildlife law violators: motivations and rationalizations. Human Dimensions of Wildlife, 9(2), 119-131. https://doi.org/10.1080/10871200490441775 
Folkbladet. (2015). Kamera vid åtel ledde till åtal [Web article]. Folkbladet 2011 [cited February 2015]. Available from http://www.folkbladet.nu/224418/kamera-vid-atel-leddetill-atal.

Foster, K. (2006). The juridification of sport. In S. Greenfield and G. Osbord (Eds.), Readings in Law and Popular Culture (pp. 155-182). London: Routledge.

Gavin, M.C., Solomon, J.N., \& Blank, S.G. (2010). Measuring and monitoring illegal use of natural resources. Conservation Biology, 24(1), 89-100. https://doi.org/10.1111/j.15231739.2009.01387.x

Gezelius, S.S. (2002). Do norms count? State regulation and compliance in a norwegian fishing community. Acta Sociologica, 4(4), 305-314. https://doi.org/10.1177/000169930204500404

Groombridge, N. (2012). Sport criminology: A critical criminiology of sport and games. CRIMSOC: Journal of Social Criminology, 1(1).

Gunn, A.S. (2001). Environmental ethics and trophy hunting. Ethics and the Environment, 6 (1), 68-95. https://doi.org/10.2979/ETE.2001.6.1.68

Gutiérrez, R.J., Howard, R.A., Jr., \& Decker, D.J. (1979). Hunting ethics, self-limitation, and the role of succinylcholine chloride in bowhunting. Wildlife Society Bulletin, 7(3), 170-172.

Habermas, J. (1996). The inclusion of the other: Studies in political theory. Boston, MA: MIT Press.

Heberlein, T.A. (1991). Changing attitudes and funding for wildlife: preserving the sport hunter. Wildlife Society Bulletin, 19(4), 528-534.

Janoski, T. (1998). Citizenship and civil society: A framework of rights and obligations in liberal, traditional, and social democratic regimes: Cambridge: Cambridge University Press. https://doi.org/10.1017/CBO9781139174787

Kellert, S. (1978). Characteristics and attitudes of hunters and anti-hunters. Paper read at North American Wildlife \& Natural Resources Conference. Phoenix, AZ.

King, R.J.H. (1991). Environmental ethics and the case for hunting. Environmental Ethics, 13(1), 59-85. https://doi.org/10.5840/enviroethics 199113117 
Krange, O., \& Skogen, K. (2007). Reflexive tradition: Young working-class hunters between wolves and modernity. Young, 15(3), 215-233. https://doi.org/10.1177/110330880701500301

Kuentzel, W.F. (1994). Skybusting and the slob hunter myth. Wildlife Society Bulletin (19732006), 22(2), 331-336.

Leopold, A. (1946). A Sand County almanac: Oxford University Press.

List, C.J. (1998). On the moral significance of a hunting ethic. Ethics and the Environment, 3(2), 157-175.

Loftin, R. (1984). The morality of hunting. Environmental Ethics, 6, 241-250. https://doi.org/10.5840/enviroethics 19846323

Long, M.A., Cross, J.E., Shelley, T.O.C., \& Kutnjak Ivković, S. (2013). The Normative Order of Reporting Police Misconduct: Examining the Roles of Offense Seriousness, Legitimacy, and Fairness. Social Psychology Quarterly, 76(3), 242-267. https://doi.org/10.1177/0190272513493094

MacDonald, K.I. (2005). Global hunting grounds: power, scale and ecology in the negotiation of conservation. Cultural Geographies, 12(3), 259-291. https://doi.org/10.1191/1474474005eu330oa

Machiavelli, N. (1965). The chief works and others. Volume 3. (A. Gilbert, Trans.). Durham: Duke University Press.

Marvin, G. (2003). A passionate pursuit: Foxhunting as performance. The Sociological Review. 51, 46-60. https://doi.org/10.1111/j.1467-954X.2004.00450.x

Marvin, G. (2007). English foxhunting: A prohibited practice. International Journal of Cultural Property, 14(03), 339-360. https://doi.org/10.1017/S0940739107070221

Marvin, G. (2013). Challenging animals - project and process in hunting. In S. Pilgrim \& J.N. Pretty (Eds.), Nature and Culture: Rebuilding Lost Connections (pp. 145-160). London: Routledge.

Mockus, A. (2003). Do constitutions constrain? Legal, moral and cultural self-bindings to prevent shortcuts. In Symposium Constitutions, democracy and the rule of law. New York: Columbia University. 
Morris, S.P. (2010). On hunting: A philosophical case study in animal sports. Columbus: The Ohio State University.

Mullings, B. (1999). Insider or outsider, both or neither: some dilemmas of interviewing in a cross-cultural setting. Geoforum, 30(4), 337-350. https://doi.org/10.1016/S00167185(99)00025-1

Noske, B. (1997). Speciesism, anthropocentrism, and non-western cultures. Anthrozoös, 10 (4):183-190. https://doi.org/10.2752/089279397787000950

Ortega y Gasset, J. (1972). Meditations on hunting: New York: Charles Scribner \& Sons.

Ostrom, E. (2005). Understanding institutional diversity. Princeton, NJ: Princeton University Press.

Pauley, J.A. (2003). The value of hunting. Journal of Value Inquiry, 37(2), 233-244. https://doi.org/10.1023/A:1025389709136

Petersen, D. (2000). Heartsblood: Hunting, spirituality and wildness in america. Washington D.C.: Island Press / Shearwater Books.

Peterson, D. (2000). Heartsblood: Hunting, spirituality, and wildness in America. Boulder: Johnson Books.

Peterson, M.N. (2004). An approach for demonstrating the social legitimacy of hunting. Wildlife Society Bulletin, 32(2), 310-321. https://doi.org/10.2193/00917648(2004)32[310:AAFDTS]2.0.CO;2

Pettit, P. (2012). On the people's terms: A republican theory and model of democracy. Cambridge: Cambridge University Press. https://doi.org/10.1017/CBO9781139017428

Pohja-Mykrä, M., \& Kurki, S. (2014). Strong community support for illegal killing challenges wolf management. European Journal of Wildlife Research, 60(5), 759-770. https://doi.org/10.1007/s10344-014-0845-9

Posewitz, J. (1994). Beyond fair chase: The ethic and tradition of hunting: Guilford, CT: Falcon Guides.

Raija, K., and Jarno, S. (2013). Identifying hunting tourist types - an exploratory case study from Finland. Tourism Review, 68(1), 48-61. https://doi.org/10.1108/16605371311310075 
Rawls, J. (1999). A theory of justice (Revised Edition). Oxford: Oxford University Press.

Rostbøll, C.F. (2008). Deliberative freedom: Deliberative democracy as critical theory. Albany: State University of New York Press.

Rubin, H., \& Rubin, I. (2011). Qualitative interviewing: The art of hearing data. Third ed: Thousand Oaks, CA: SAGE Publications.

Samuel, D. (1999). Know hunting: truths, lies and myths. Cheat Lake: Know Hunting Publications.

Scruton, R. (2000). Animal rights and wrongs. New York: Claridge Press.

Simpson, S.V., \& Cain, K.D. (2000). Recreation's role in the environmental ethics dialogue: the case of aldo leopold and the morality of hunting. Leisure/Loisir, 25(3-4), 181-197. https://doi.org/10.1080/14927713.2000.9649916

St John, F., Edwards-Jones, G., \& Jones, J. (2010). Conservation and human behaviour: lessons from social psychology. Wildlife Research, 37(8), 658-667. https://doi.org/10.1071/WR10032

Thomsen, D.A., \& Davies, J. (2007). Rules, norms and strategies of kangaroo harvest. Australasian Journal of Environmental Management, 14(2), 123-130. https://doi.org/10.1080/14486563.2007.10648709

Wade, M.L. (1990). Animal Liberationism, Ecocentrism, and the morality of sport hunting. Journal of the Philosophy of Sport, 17(1), 15-27. https://doi.org/10.1080/00948705.1990.9714475

Wall, T., \& McClanahan, B. (2015). Weaponizing conservation in the 'heart of darkness': the war on poachers and the neocolonial hunt. In A. Brisman, R. White and N. South. Ashgate (Eds.), Environmental crime and social conflict: Contemporary and emerging issue (pp. 221-238). London: Routledge

Wam, H.K., Pedersen, H.C., \& Hjeljord, O. (2012). Balancing hunting regulations and hunter satisfaction: An integrated biosocioeconomic model to aid in sustainable management. Ecological Economics, 79(July), 89-96. https://doi.org/10.1016/j.ecolecon.2012.04.022

Van de Pitte, M. (2003). The moral basis for public policy encouraging sport hunting. Journal of Social Philosophy, 34(2), 256-266. https://doi.org/10.1111/1467-9833.00179 
International Journal of Rural Criminology, Volume 4, Issue 1 (July), 2018

von Essen, E., Hansen, H.P., Nordström Källström, H., Peterson, M.N., \& Peterson, T.R. (2015). The radicalisation of rural resistance: How hunting counterpublics in the Nordic countries contribute to illegal hunting. Journal of Rural Studies, 39, 199-209.

https://doi.org/10.1016/j.jrurstud.2014.11.001 